\title{
PREVALENCE AND ECONOMIC SIGNIFICANCE OF BOVINE FASCIOLOSIS IN CATTLE SLAUGHTERED AT DEBRE-TABOR MUNICIPAL ABATTOIR
}

\author{
Mastewal BIRHAN ${ }^{\star 凶}$ Gedefaw DEMEWEZ ${ }^{2}$, Tewodros FENTAHUN ${ }^{1}$ and Tadegenge MITIKU1 \\ 1 University of Gondar, Collage of Veterinary Medicine and Animal Sciences, Department of Veterinary Paraclinical Studies, Ethiopia \\ 2South Gondar Zone Livestock Resource Development Office, Amhara Regional State, Ethiopia \\ Email: maste675@gmail.com, ORCID: 0000-0002-0984-5582 \\ supporting Information
}

\begin{abstract}
A cross sectional study was carried out from January, 2018 to June 2018 to determine the abattoir prevalence and economic loss associated with fasciolosis in cattle slaughter at Debretabor municipal abattoir. From the total of 350 examined cattle, 100 (28.6\%) were positive for fasciolosis. Highest prevalence was observed in poor body condition cattle 26 (45.6\%) followed by medium 54 (26.7\%) and good body condition cattle 20 (22\%), respectively. There was also significant difference in different age group. The highest 18 (40.9\%) prevalence was in young cattle and the lowest $82(26.8 \%)$ found in adult animals. Also the prevalence of bovine fasciolosis was highest in local breed 90 (32.2\%) than in cross breed 7 (3.3\%) with statistical significant difference $(\mathrm{P}<0.05)$. The total annual economic loss was estimated 60746.4 ETB. The study showed that the prevalence and money loss due to fasciolosis in cattle slaughtered at Debretabor municipal abattoir was high. Hence, immediate prevention and control of fasciola is needed.
\end{abstract}

Keywords: Cattle, Debretabor, Economic significance, Fasciolosis, Prevalence

\section{INTRODUCTION}

Ethiopia owns huge number of ruminants having high contribution for meat consumption and generates cash income from export of live animals, meat, edible organs and skin. In spite of the presence of huge ruminant population, Ethiopia fails to optimally exploit these resources due to a number of factors such as recurrent drought, infrastructures problem, rampant animal diseases, poor nutrition, poor husbandry practices, shortage of trained man power and lack of government policies for disease prevention and control. Cattle suffer from a variety of infection and non- infectious diseases. They may harbor several helminthes parasite (Andrews et al., 1992).

In Ethiopia both fasciola hepatica and fasciola gigantica have the greatest risk occurred in areas of extended high annual rainfall associated with high soil moisture and surplus water, with risk diminishing in areas of shorter wet season and lower temperatures. For fasciola gigantica regions in the high lands of Ethiopia and Kenya were identified as unsuitable due to in adequate thermal regime. Average annual mean temperatures of $23^{\circ} \mathrm{C}$ or above were found to correspond to areas below the $1200 \mathrm{~m}$ elevation limit of fasciola hepatica in Ethiopia (Malone et al., 1998).

Several abattoir surveys conducted in various parts of Ethiopia have demonstrated the presence of fasciolosis, due to $f$. Hepatica and $f$. Gigantica, in ruminants. Some studies tried to demonstrate the economic losses associated with liver condemnation and evaluation of the economic loss due to fasciolosis differ in different parts of Ethiopia (Tolosa et al., 2007; Fufa et al., 2008; Gbratsadik et al., 2009; Nraddis et al., 2010 and Kassaye et al., 2012). The objective of the study was to determine the abattoir prevalence and economic loss associated with fasciolosis in cattle slaughter at debretabor municipal abattoir.

\section{MATERIAL AND METHODS}

\section{Description of the study area}

The study was conducted in Debretabor Municipal abattoir from January, 2018 to June 2018. Debretabor is found in south Gondar zone, Amhara regional state, Ethiopia. It is located at $670 \mathrm{~km}$ North of Addis Ababa. The minimum and maximum annual rain fall and daily temperature ranges between 1000 to $1500 \mathrm{~mm}$ and 20 to $25^{\circ} \mathrm{C}$, respectively (SGAO, 2012).

\section{Study design}

Active abattoir survey was conducted based on cross sectional study during routine meat inspection on randomly selected cattle slaughtered at Debretabor municipal abattoir from January, 2018 to June 2018. 


\section{Sampling technique}

A cross sectional study was carried to determine the prevalence of bovine fasciolosis. Random sampling technique was use to collect all the necessary data from abattoir survey of the study animals.

\section{Study methodology}

The liver of each study animal was carefully examined for presence of lesions suggestive of Fasciola infection externally and sliced for confirmation. Liver flukes were recovered for differential count by incising the infected liver into fine, approximately $1 \mathrm{~cm}$ slices with a sharp knife. Each mature fluke was identified to species level according to its shape and size. Investigation and identification of Fasciola was done according to their distinct morphological characteristics following the standard guidelines given by Urquhart et al. (1996).

\section{Sample size determination}

The sample size was calculated according to Thrusfield (2005) by considering $27.7 \%$ expected prevalence from previous study and $5 \%$ desired absolute precision at $95 \%$ confidence level using the following formula.

$$
\mathbf{N}=\left((1.96)^{2}\left(P_{\exp }\right)\left(1-P_{\exp }\right)\right.
$$

$$
\mathrm{d}^{2}
$$

$\mathbf{N}=$ Total number of sample size represented a considerable economic and public health; $P_{\exp }=$ Expected prevalence; $d=$ Absolute precision. Therefore, the sample was about 308 . But to increase the accuracy of the study the determined sample size was 350 .

\section{Study animals}

The study animals were cross breed and indigenous zebu cattle brought from various localities to Debretabor municipal abattoir for slaughtering.

\section{Economic loss assessments}

Generally, all infected livers with fasciolosis were considered to be unfit for human consumption and if any liver was infected by Fasciola at the Debretabor municipal abattoir, it was totally condemned. Economic losses were calculated based on condemned livers due to fasciolosis. In the study abattoir, the average annual cattle slaughtered rate was estimated to be 3540, while mean retail price of bovine liver in Debretabor town was 60 ETB. The prevalence of bovine fasciolosis in Debretabor municipal abattoir was estimated as $28.6 \%$. The estimated annual loss from organ condemnation is calculated according to mathematical computation using the formula set by Ogunrinade and Adegoke (1982):

$A L C=C S R \times L C \times P ;$ Where ALC = Annual loss from liver condemnation, CSR = mean annual cattle slaughtered at Debretabor municipal abattoir, LC = mean cost of one liver in Debretabor town, $\mathrm{P}=$ prevalence of bovine fasciolosis at Debre tabor municipal abattoir.

\section{Data analysis}

Data obtained from postmortem findings in the abattoir uploaded into Microsoft Excel 2007 spreadsheet computer program. Then, it was analyzed by using SPSS version $\mathbf{1 6 . 0}$ for windows software and Chi-square $\left(\mathrm{x}^{2}\right)$ test is applied to compare the infection status with regard to the hypothesized risk factor like age, body condition, and breed. But comparison regarding sex was not made since all cattle brought to the abattoir were male. P-valve $<0.05$ was accepted as statistically significant in all cases.

\section{RESULT AND DISCUSSION}

Out of 350 male cattle that were slaughtered at Debretabor municipal abattoir $100(28.6 \%)$ animals were found infected with liver fluke. The prevalence of fasciolosis was highest in local breed 93(32.2\%) and lowest in cross breed 7(3.3\%) (Table 1). There was a statistically significant difference $(\mathrm{P}<0.05)$ in the prevalence of bovine fasciolosis in different age groups. The highest (40.9\%) prevalence was in young animals and the lowest $(26.8 \%)$ was found in adult animals (Table 2). There was a significant difference $(P<0.05)$ in the prevalence of bovine fasciolosis within different body condition scores. The highest prevalence (45.6\%) was found in cattle with poor body condition scores and the lowest prevalence (22 \%) was found in good body conditioned animals (Table 3 ). The economic significance of fasciolosis was analyzed based on the information obtained during postmortem examination and interview. Annual loss due to liver condemnation $=£ C S \times \operatorname{coy} \times$ Roz $=3540 \times 60 \times 28.6 \%=60746.4$ Ethiopian Birr was annual lost.

Fasciolosis is widespread ruminant health problem that is regard as one of the major setback to livestock production causing huge direct economic losses in Ethiopia that were reported by many workers. The current findings $28.6 \%$ at abattoir revealed that the prevalence in debretabor municipal abattoir is lower than $46.15 \%$ recorded in Jimma municipal abattoir (Tadele and Worku, 2007) and greater than 24.32\% in Mekele municipal abattoir (Berhe et al., 2009) and 14\% recorded at Wolaita Soddo municipal abattoir (Fufa et al., 2009). Thus, the most reasonable condition for the presence of different prevalence from area to area through the country is due to the availability of suitable snail habitats. The result of the current study showed that age has significant effect on the prevalence of bovine fasciolosis. The prevalence was higher in young animals 
than the adult. There was a decrease in infection rate (prevalence) as age increased. This may be due to the result of acquired immunity with age which is manifested by humoral immune response and tissue reaction in bovine liver due to previous challenge. There are some additional reports confirming that the increased resistance against fasciolosis (low prevalence) with age is most likely related to the high level of tissue reaction seen in bovine liver. Liver fibrosis which impedes the passage of immature flukes acquired thickening, stenosis and calcification of bile ducts, assumed unfavorable site for adult parasites and consequently fasten their expulsion. These are in agreement with experimental study conducted by Radostits et al. (2007) which confirmed the occurrence of higher infection rate in younger animals. The results of the present study indicated that body condition of the animal has significant association with the occurrence of fasciolosis.

The prevalence was higher in poor body conditioned cattle than that of medium and good body conditioned cattle's. The prevalence of fasciolosis was higher in the animals with poor body condition because this body condition in cattle is manif ested when fasciolosis reaches at its chronic stage. The present finding is by far lower than the results reported by Abdul (1992) and Daniel (1995) who reported a total economic loss of 154,188 and 215,000 ETB, respectively annually in cattle due fasciolosis at Ziway and Dire-Dawa municipal abattoir, respectively. These higher values may be due to higher number of animals slaughtered at the Dire-Data and Ziway abattoirs. The ecological conditions and the number of intermediate host found around the area may also be another factor contributing to the decrement of the economic losses.

Table 1 - Prevalence of fasciolosis in local breed

\begin{tabular}{lcccc} 
Breed & Number of examined cattle & Prevalence (\%) & X'value & P -value \\
\hline Local & 289 & $93(32.2 \%)$ & 10.58 & 0.001 \\
Cross & 61 & $7(3.3 \%)$ & & - \\
Total & 350 & $100(28.6 \%)$ & - & - \\
\hline
\end{tabular}

\section{Table 2 - Prevalence of bovine Fasciola based on age}

\begin{tabular}{lcccc} 
Age & Number of Examined Cattle & Prevalence (\%) & $X^{2}$ value & P -value \\
\hline Adult & 306 & $82(26.8 \%)$ & 103.841 & 0.010 \\
Young & 44 & $18(40.9 \%)$ & & - \\
Total & 350 & $100(28.6 \%)$ & - & - \\
\hline
\end{tabular}

Table 3 - Prevalence Of Bovine Fasciola In Association With Body Condition Score

\begin{tabular}{lcccc} 
Good & Number Of Examined Cattle & Prevalence (\%) & X2 Value & P-Value \\
\hline Good & 91 & $20(22 \%)$ & 9.77 & 0.008 \\
Medium & 202 & $54(26.7 \%)$ & - & - \\
Poor & 57 & $26(45.6 \%)$ & & \\
Total & 350 & $100(28.6 \%)$ & & \\
\hline
\end{tabular}

\section{CONCLUSION}

In conclusion the current study disclosed that bovine fasciolosis an important disease causing major economic loss in Debretabor municipal abattoir. Based on the finding the following recommendation would be forwarded. Strategic deworming should be applied. Society should be well informed about the disease importance. Locally available control practice should be practiced just like by planting trees having molluscides activity (Endod).

\section{DECLARATIONS}

\section{Acknowledgment}

The authors' heartfelt thanks will also go to University of Gondar, Vice President of Research and Community Service, Collage of Veterinary Medicine and Animal Science for the financially supporting the article processing.

\section{Authors' contributions}

MB conceived the study, coordinated the overall activity, and carried out the statistical analysis, drafted the manuscript and participated in the design of the study, and reviewed the manuscript. All authors read and approved the final manuscript. GD participated in drafting, reviewing the manuscript and conceived the study, coordinated the overall activity, and reviewed the manuscript and participated in drafting and reviewing the manuscript.

\section{Availability of data and materials}

Data will be made available up on request of the primary author

\section{Consent to publish}

Not applicable.

\section{Competing interests}

The authors declare that they have no competing interests. 


\section{REFERENCE}

Abdul J (1992). Economic significance of bovine fasciolosis and hydatidiosis in soddo, DVM thesis, Faculty of Veterinary Medicine, Addis Ababa University Debrezeit, Ethiopia.

Andrews H, Bloweey W, Boy Eddly G (1992). Bovine Medicine disease and Husbandary of cattle. 1'st edition. Blackwell science LTD. Pp. 238.

Berhe G, Berhane K, Tadesse G (2009). Prevalence and economic significance of fasciolosis in cattle in Mekelle area of Ethiopia. Tropical Animal Health and Production. 12: 106-109.

Daniel F (1995). Economic Importance of organ condemnation due to Fasciolosis and Hydatidosis in Cattle and Sheep slaughtered at Dire Dawa abattoir, DVM, Thesis, Faculty of Veterinary Medicine. Addis Ababa University, Debrezeit, Ethiopia. Tropical Animal Health and Production. pp. 18-26.

Fufa A, Loma A, Bekele M and Alemayehu R (2009). Bovine fasciolosis: coprological, abattoir survey and its economic impact due to liver condemnation at Soddo municipal abattoir, Southern Ethiopia. Tropical Animal Health and Production 42(2): $289-292$.

Gebretsadik B, Kassahun B and Gebrehiwot (2009). Prevalence and economic significance of fasciolosis in cattle in Mekelle Area of Ethiopia. Tropical Animal Health and Production 41(7): 1503-1504.

ILRI (2009). Management of vertisols in Sub-Saharan Africa, Proceedings of a Conference Post-mortem differential parasite counts FAO corporate document repository.

Kassaye N, Yehualashet D, Yifat and Desie S (2012). Fasciolosis in Slaughtered Cattle in Addis Ababa Abattoir, Ethiopia. Global Veterinarian, 8: 115-118.

Malone B, Gommes R, Hansen J, Yilma M, Slingenberg J, Snijders F, Nachtergaele F, Ataman E. 1998 A geographic information system on the potential distribution and abundance of Fasciola hepatica and F. gigantic in east Africa based on Food and Agriculture Organization databases. Veterinary Parasitology, 78: 87 -101.

Nuraddis I, Wasihun P and Tolosa T (2010). Prevalence of Bovines Fasciolosis and Economic Importance due to Liver Condemnation at Kombolcah Industrial Abattoir, Ethioipia. The Internet Journal of Veterinary Medicine, 8(2).

Ogunrinade A, Adegoke G (1982). Bovine fasciolosis in Nigeria intercurrent parasitic and bacterial infection. Tropical Animal Health and Production. 14: 121-125.

Radostits D, Blood B, Gray C. (2007). Vet medicine text book of the diseases of cattle, sheep, goat, pig and horse8th edit ELBS and Bailleretindal.

South Gondar zone agricultural office (2012).

Tadele T and Worku T (2007). The prevalence and economic significance of Bovine fasciolosis at jimma abattoir, Ethiopia.

Thrusfield M (2005). Veterinary Epidemiology. $3^{\text {rd }}$ edition. Singapore, Black Well Science, 233-236.

Tolosa T and Tigre W (2007). The prevalence and economic significance of Bovine fasciolosis at JimmaAbattoir, Ethiopia. The Internet Journal of Veterinary Medicine, 3(2)

Urquhart G, Armour J, Dunn A, Jennings F, Duncan L (1996). Veterinary Parasitology. Veterinary Parasitology. $2^{\text {nd }}$ Edition, Blackwell Science Ltd., Oxford, 224-234. 